\title{
Dropped head syndrome in systemic lupus eritematoso (SLE): Case report and review of the neurological manifestations of LES
}

\author{
Oliveira FTM ${ }^{1 *}$, Pellegrinelli $A^{1}$ and Gennari JD ${ }^{2}$ \\ ${ }^{1}$ Department of Neurology, Santa Casa of São Paulo-SP, Brazil \\ ${ }^{2}$ Department of Rheumatology, Santa Casa of São Paulo-SP, Brazil
}

\begin{abstract}
The dropped head syndrome (DHS) is a weakness of neck extension, leading to a typical presentation of the flexed head with the chin in contact with the chest wall. We report a case of a patient with DHS due to vasculitis of the CNS secondary to SLE and performed a brief review of the literature on the subject. SLE is a systemic disease with several neurological manifestations, the prompt recognition of these conditions usually leads to a better long-term prognosis from a functional point of view. We show the main complications and an example of a successful case due to the prompt care of the neurology and rheumatology.
\end{abstract}

\section{Case report}

L.B.O., 38 years old, in follow-up at our service by SLE, with involvement of CNS previously (cerebral vasculitis secondary to lupus activity), using corticoid therapy and immunosuppressant (azathioprine). Patient in clinical stability and in weaning of corticoid, presented with clinical picture of fallen head, dysphagia, dysphonia and tetraparesis, with muscular strength global IV, deep tendon reflexes 4+ global, and superficial hypoesthesia, with a sensitive level in C6. He underwent partial-response methylprednisolone pulse therapy, evolving with septic pulmonary focus. After intravenous cyclophosphamide treatment, the patient presented motor and sensory improvement. The study of cerebrospinal fluid by lumbar puncture showed inflammatory activity, without changes in the research of infectious agents. Performed MRI of the brain and cervical and thoracic columns, which showed signs suggestive of cerebral vasculitis and cervical spinal cord.

\section{Introduction}

Systemic Lupus Erythematosus (SLE) is a chronic systemic autoimmune disease of connective tissue with various clinical manifestations, characterized by periods of exacerbation and remission. This disease has a marked characteristic, the exacerbated production of antibodies (anti-DNA, anti-Sm, anti-RNP, anti-Ro / SSa, anti-La / SSb, among others).

There are no definitive criteria for the diagnosis of SLE. The American College of Rheumatology defined classification criteria for SLE, according to which at least four clinical and/or laboratory criteria are necessary among eleven after careful investigation and exclusion of infectious, neoplastic, and other diseases [1,2].

The criteria consider the following manifestations:

$$
\begin{aligned}
& \text { - Malar rush } \\
& \text { - Discoid lesion }
\end{aligned}
$$$$
\text { - Photosensitivity }
$$

\section{- Oral mucous ulcers}

- Non-deforming arthritis

- Serositis (pleuritis, pericarditis).

- Renal disease (persistent proteinuria, cylindrury).

- Involvement of the central nervous system (convulsion and psychosis).

- Hematological changes (anemia, leucopenia or thrombocytopenia). - Immunological changes: anti-DNA, anti-Sm or false positive VDRL.

- Anti-nuclear factor (ANF)

\section{Neurological manifestations of SLE}

Neurological manifestations in SLE are complex and can be defined as: neurological manifestations of the central nervous system (CNS), peripheral (PNS), autonomic (ANS) and psychiatric syndromes.

These manifestations may be caused directly by SLE activity or be secondary to comorbidities such as systemic arterial hypertension (SAH), diabetes mellitus (DM), uremia, and infection.

Patients with SLE may present CNS involvement with a very variable frequency, 14 to $75 \%$, depending on the population studied and the inclusion criteria used. Probably the main reason for the huge statistical differences found in the frequency of CNS involvement is the inclusion of minor non-specific symptoms.

Due to the fact that clinical manifestations may be caused directly by SLE activity or occur secondary to comorbidities, it is difficult to

Correspondence to: Oliveira FTM, Department of Neurology, Santa Casa at São Paulo- SP, Av. Dr Cesario Mota Jr, 112 - V. Buarque. São Paulo-SP, Brazil, CEP 01221-010; E-mail: towmaz@gmail.com

Received: November 27, 2017; Accepted: January 0, 2018; Published: January 09,2018 


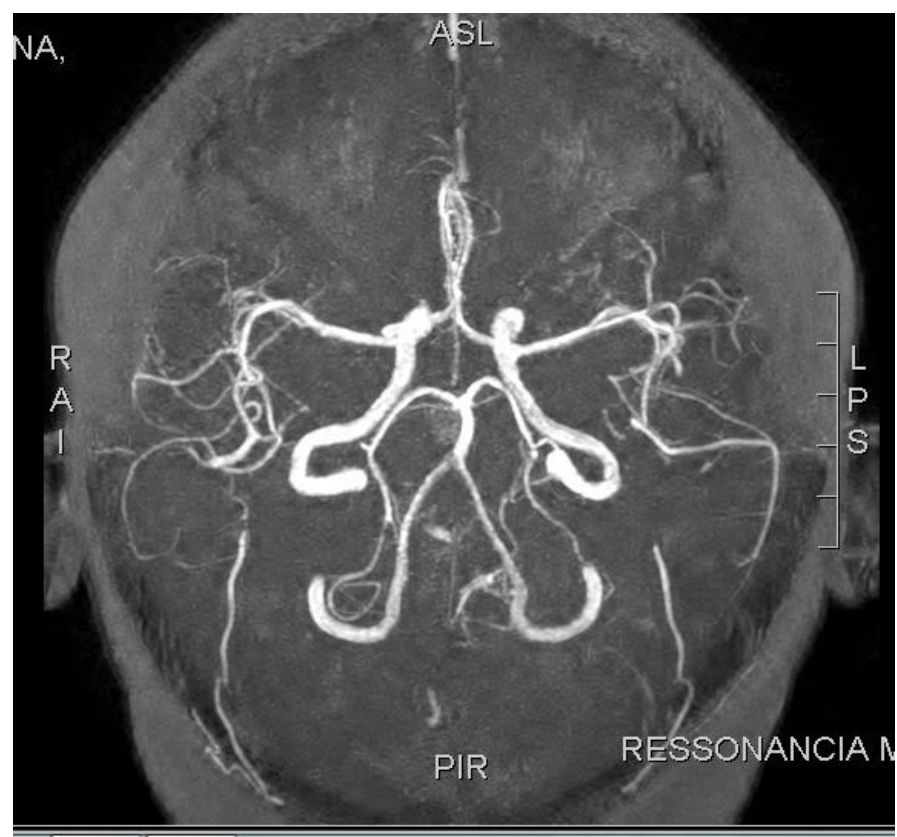

Figure 1. Angiographic study of venous drainage of the encephalon without alterations and intracranial arteries with inflammatory vasculopathy.

define which changes should be attributed directly to SLE, or which are secondary to the treatment performed or to other associated conditions.

The neuropsychiatric manifestations of SLE are divided into 2 subgroups, according to the American College of Rheumatology (ACR) in 1999: CNS manifestations (headache, convulsion, anxiety disorder, mood disorder, movement disorders, cognitive disorders, cerebrovascular disease, confusional state acute, aseptic meningitis, myelopathy, psychosis, demyelinating syndromes) and manifestations of PNS (autonomic disorder, Myasthenia Gravis, mononeuropathy, cranial neuropathy, plexopathy, polyneuropathy, acute demyelinating inflammatory polyradiculopathy). Major CNS manifestations according to RTA definitions would include: chorea, aseptic meningitis, psychosis, convulsions, myelopathy, demyelinating syndrome, acute confusional state, and stroke [1-9].

The importance of early recognition, clinical and laboratorial analysis and adequate treatment of CNS manifestations in SLE are due to the influence of this influence on mortality, quality of life and permanent functional impairment.

The difference in the numbers of CNS involvement in the literature shows that a better study of this involvement is important, mainly because the long-term repercussions of this possibly underdiagnosed condition can lead to a great functional compromise and the quality of life of the CNS. patients. This involvement of the CNS in SLE is complex because it involves multiple clinical presentations. The ACR classified these changes into 19 syndromes, 12 of which were CNS (major: aseptic meningitis, cerebrovascular diseases, demyelinating syndrome, movement disorders, epilepsy, myelopathy, psychosis, acute confusional state, and minor ones: headache, anxiety disorder, mood and cognitive impairment) and 7 of the PNS (Guillain Barré syndrome, autonomic neuropathy, mononeuropathy, myasthenia gravis, cranial neuropathy, plexopathy, polyneuropathy).

Histopathological studies in patients with SLE have often found a vasculopathy of small intracranial vessels consisting of proliferative changes of the intima, vascular hyalinization and perivascular
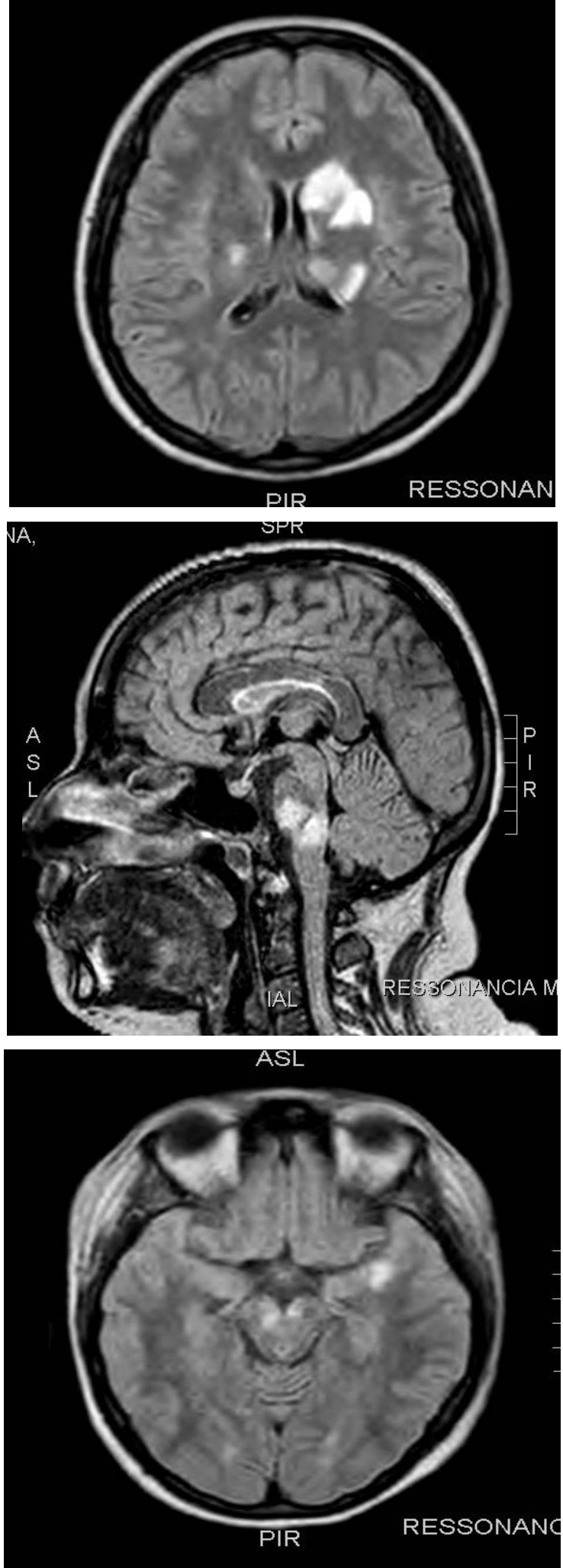

Figures 2 to 4 . Multiple signal alteration foci characterized by the hypersignal in T2 and FLAIR located in the trunk of the corpus callosum, nucleocapsular regions, thalamus. The parenchymal changes observed in the thalamus and posterior arm of the internal capsule (nodular enhancement to paramagnetic contrast medium and restriction to the free movement of water molecules, compatible with foci of subacute ischemia) should result from probable inflammatory vascular changes related to the underlying disease inflammatory vasculopathy. 


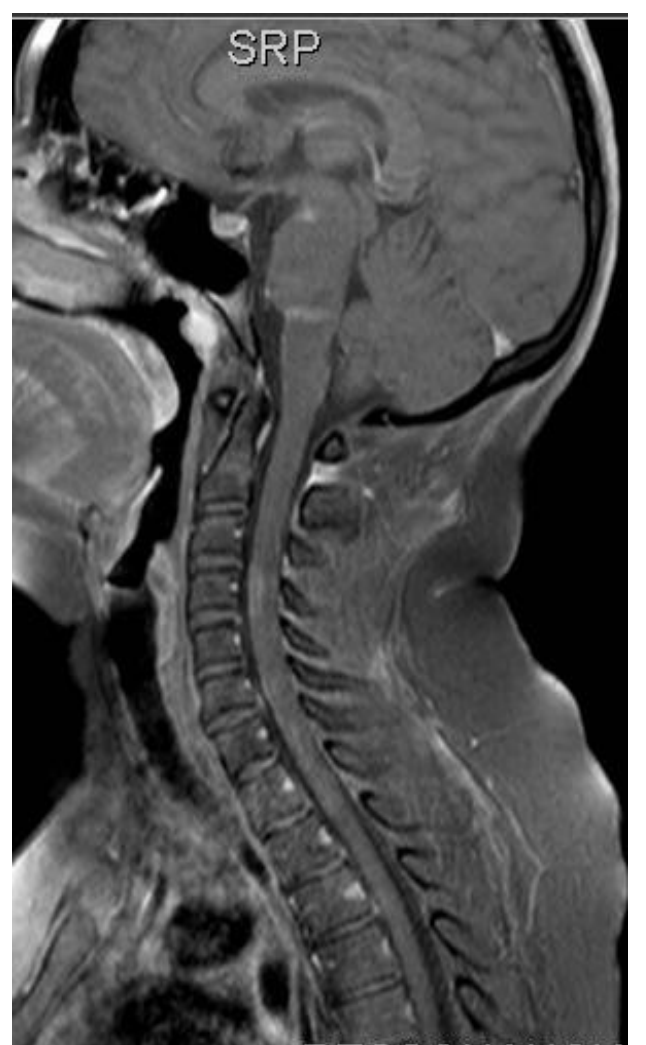

Figure 5. Signal alteration compromising the spinal cord at $\mathrm{C} 3-\mathrm{C} 4$ levels in $\mathrm{T} 2$ FLAIR, with impregnation by the paramagnetic contrast agent, which should result from inflammatory vascular changes related to the underlying disease, corroborating the hypothesis of inflammatory vasculopathy (vasculitis).

lymphocytosis. This vasculopathy of small vessels was seen in both SLE with psychiatric symptoms and in those with focal manifestations. Studies with SPECT and MRI of the skull with spectroscopy suggest that both cerebral atrophy and cognitive decline in SLE patients may be related to chronic cerebral schistosomiasis [10-12]

The production of autoantibodies has been implicated in this vasculopathic process and associated with neuronal injury, mainly anti-P antibodies and antiphospholipid antibodies, with a strong correlation with the major manifestations of CNS involvement in SLE [12-14].

Antiphospholipid antibodies are members of a family of antibodies directed against plasma proteins bound to negatively charged phospholipids, which lead to hypercoagulability through effects on protein $\mathrm{C}$, protein $\mathrm{S}$, platelets, endothelial cells and complement activation. Antiphospholipid antibodies, defined as lupus anticoagulant, anticardiolipin and anti-b2 glycoprotein-1 (anti-b2GP1), are strongly associated with transient ischemic attack (TIA), stroke, seizures, and cerebral venous thrombosis [15].

Cerebral ischemic events may occur early in the course of SLE, or may even precede the diagnosis, leading to the diagnosis of underlying SLE. The frequency of cerebrovascular disease as a whole ranges from 5.3 to $19 \%$, depending on the study methodology and the neuropsychiatric syndromes included in the series. Cerebral venous thrombosis is a rare complication, and as well as hemorrhagic stroke, intracerebral hemorrhage and arachnoid, can also occur in SLE. The association between Antiphospholipid Syndrome and venous or arterial thrombotic events has been described in both the primary antiphospholipid syndrome and the secondary SLE [16-20].
Cranial neuropathies occur more frequently from II to VII cranial nerves, causing ocular manifestations, either as isolated internuclear ophthalmoplegia or as paralysis of II, IV or VI nerves.

A demyelinating syndrome can cause motor deficit in one or more limbs, secondary to transverse myelopathy, or diplopia due to optic neuropathy, isolated nerve palsy or internuclear ophthalmoplegia.

Some studies are recommended in the evaluation of all patients with possible demyelinating syndrome, including evaluation:

1) CSF: for cell counts, proteins, oligoclonal bands, IgG index, cultures and cytology;

2) MRI of the brain, and according to the clinical picture, evoked potentials.

The differential diagnosis of demyelinating syndromes includes structural lesions, familial disorders such as ataxia and leukodystrophies, sarcoidosis, Behçet's syndrome, optic neuromyelitis and its spectrum of presentations, multiple sclerosis, and the exclusion of infectious diseases (tuberculosis, HIV, syphilis) and deficits nutritional deficiencies (vitamin B12 deficiency)

Probably the main reason for the huge statistical differences found in the frequency of CNS involvement is the inclusion of minor nonspecific symptoms, including headache, mild cognitive impairment and depressive symptoms, which may occur in several chronic autoimmune diseases, patients treated with steroids and immunosuppressants, with difficult characterization as disease activity, independent diseases or consequence of the various associated comorbidities. Hence the importance of larger studies showing the actual frequency of major manifestations of CNS involvement by SLE [13,21-30].

The presentation of DHS in a patient with SLE is relatively rare, being more common in patients with neurological diseases, such as [31]:

- Degenerative diseases: Amyotrophic lateral sclerosis, Parkinson's disease, Multiple system atrophy;

- Movement disorders: cervical dystonia, tardive dyskinesia;

- Neuromuscular: Myasthenia Gravis, Post-polio syndrome, Lambert-Eaton myasthenic syndrome, Chronic inflammatory polyradiculoneuropathy. Muscle involvement may be inflammatory or non-inflammatory, or secondary.

- Inflammatory primary muscle: polymyositis;

- Non-inflammatory primary muscle: nemaline myopathy, inclusion corpuscle myopathy, mitochondrial myopathies, congenital myopathies;

- Secondary muscle: post-radiation, post-toxin botulinum, hypokalemia, hypothyroidism.

\section{Conclusion}

We present a rare case of DHS secondary to CNS involvement due to cervical myelitis secondary to vasculitic activity. We verified through this broad review that the SCC has several etiologies (myogenic, neurogenic, metabolic, degenerative and local causes), and that within the context of rheumatologic autoimmune diseases, an extensive investigation becomes important because the therapeutic behavior can vary widely, including broadly altering the long-term functional prognosis of these patients. 


\section{References}

1. Tan EM, Cohen AS, Fries JF, Masi AT, Mcshane DJ, et al. (1982) The 1982 Revised Criteria for the Classification of SLE. Arthritis and Rheumatism 25: 1271-1277. [Crossref]

2. Jonsson H, Nived O, Sturfelt G (1989) Outcome in systemic lupus erythematosus: a prospective study of patients from a defined population. Medicine (Baltimore) 68: 141150. [Crossref]

3. Feng PH, Cheah PS, Lee YK (1973) Mortality in systemic lupus erythematosus: a 10year review. Br Med J 4: 772-774. [Crossref]

4. Dubois EL, Tuffanelli DL (1964) Clinical manifestations of systemic lupus erythematosus: computer analysis of 520 cases. JAMA 190: 104-111. [Crossref]

5. Costallat LTL, Appenzeller S, Marini R (2002) Evolução e fatores prognósticos do lúpus eritematoso sistêmico em relação com a idade de início. Rev Bras Reumatol 42: 91-98

6. Costallat LT, Appenzeller S, Bértolo MB (2001) Lupus neuropsiquiátrico de acordo com a nova nomenclatura e definição de casos do Colégio Americano de Reumatologia (ACR): análise de 527 pacientes. Rev Bras Reumatol 41: 133-141.

7. Cheatum DE, Hurd ER, Strunk SW, Ziff M (1973) Renal histology and clinical course of systemic lupus erythematosus. A prospective study. Arthritis Rheum 16: 670-676. [Crossref]

8. ACR Ad hoc Committee on Neuropsychiatric Lupus Nomenclature (1999) The American College of rheumatology Nomenclature and Case definitions for Neuropsychiatric Lupus syndromes. Arthritis Rheum 42: 599-608

9. Ginzler EM, Diamond HS, Weiner M, Schlesinger M, Fries JF, et al. (1982) A multicenter study of outcome in systemic lupus erythematosus. I. Entry variables as predictors of prognosis. Arthritis Rheum 25: 601-611. [Crossref]

10. Abreu MR, Jakosky A, Folgerini M, Brenol JC, Xavier RM, et al. (2005) Neuropsychiatric systemic lupus erythematosus: correlation of brain MR imaging, CT, and SPECT. Clin Imaging 29: 215-221. [Crossref]

11. Ainiala H, Loukkola J, Peltola J, Korpela M, Hietaharju A (2001) The prevalence of neuropsychiatric syndromes in systemic lupus erythematosus. Neurology 57: 496-500. [Crossref]

12. Brey RL, Holliday SL, Saklad AR, Navarrete MG, Hermosillo-Romo D, et al. (2002) Neuropsychiatric syndromes in lupus: prevalence using standardized definitions. Neurology 58: 1214-1220. [Crossref]

13. Carlomagno S, Migliaresi S, Ambrosone L, Sannino M, Sanges G, et al. (2000) Cognitive impairment in systemic lupus erythematosus: a follow-up study. $J$ Neurol $247: 273-279$. [Crossref]

14. Costallat LTL, Oliveira RM, Santiago MB, Cossermelli W, Samara AM (1990) Neuropsychiatric manifestations of SLE: the value of anticardiolipin, antigangliosides and antigalactocerebrosides antibodies. Clin Rheum 4: 489-497. [Crossref]

15. Gibbs NA, Moroney J, Foley-nolan D, O'connell PG (2002) Neuromyelitis óptica (Devic's syndrome) in systemic lúpus erythematosus: a case report. Rheumatol 41: 470-477.
16. Hanly JG, Mccurdy G, Fougere L, Douglas JA, Thompson K (2004) Neuropsychiatric events in systemic lupus erythematosus: attribution and clinical significance. $J$ Rheumatol 32: 2156-2162. [Crossref]

17. Hanly JG, Harrison MJ (2005) Management of neuropsychiatric lupus. Best Pract Res Clin Rheumatol 19: 799-821. [Crossref]

18. Hanly JG, Fisk JD, Mccurdy G, Fougere L, Douglas JA (2005) Neuropsychiatric syndromes in patients with systemic lupus erythematosus and rheumatoid arthritis. $J$ Rheumatol 32:1459-1456. [Crossref]

19. Jonsen A, Bengtsson AA, Nived O, Ryberg B, Sturfelt G (2002) Outcome of neuropsychiatric systemic lupus erythematosus within a defined Swedish population: increased morbidity but low mortality. Rheumatology (Oxford) 41: 1308-1312. [Crossref]

20. Karassa FB, Ioannidis JP, Boki KA, Touloumi G, Argyropoulou MI, et al (2000) Predictors of clinical outcome and radiologic progression in patients with neuropsychiatric manifestations of systemic lupus erythematosus. Am J Med 109: 628634. [Crossref]

21. Kovacs JA, Urowitz MB, Gladman DD (1993) Dilemmas in neuropsychiatric lupus. Rheum Dis Clin North Am 19: 795-814. [Crossref]

22. Lee P, Urowitz MB, Bookman AA, Koehler BE, Smythe HA, et al. (1977) Systemic lupus erythematosus. A review of 110 cases with reference to nephritis, the nervous system, infections, aseptic necrosis and prognosis. QJ Med 46: 1-32. [Crossref]

23. Mikdashi J, Handwerger B (2004) Predictors of neuropsychiatric damage in systemic lupus erythematosus: data from the Maryland lupus cohort. Rheumatology (Oxford) 43:1555-1560. [Crossref]

24. Mok CC, Lau CS, Wong RW (2001) Neuropsychiatric manifestations and their clinical associations in southern Chinese patients with systemic lupus erythematosus. $J$ Rheumatol 28: 766-7671. [Crossref]

25. Navarrete MG, Brey RL (2000) Neuropsychiatric Systemic Lupus Erythematosus. Curr Treat Options Neurol 2: 473-485. [Crossref]

26. Primavera A, Audenino D, Mavilio N, Cocito L (2001) Reversible posterio leucoencephalopathy syndrome in systemic lupus and vasculitis. Ann Rheum Dis 60: 543-547. [Crossref]

27. Reichlin M (2003) Ribosomal P antibodies and CNS lupus. Lupus 12: 916-918. [Crossref]

28. Robert M, Sunitha R, Thulaseedharan NK (2006) Neuropsychiatric manifestations systemic lúpus erythematosus: a study from South India. Neurol India. 54: 75-77. [Crossref]

29. Sergent JS, Lockshin MD, Klemperer MS, Lipsky BA (1975) Central Nervous system disease in systemic lupus erythematosus: theraphy and prognosis. Am J Med 58: 644 654. [Crossref]

30. Swaak AJ, Nossent JC, Bronsveld W, Van Rooyen A, Nieuwenhuys EJ, et al. (1989) Systemic lupus erythematosus. I. Outcome and survival: Dutch experience with 110 patients studied prospectively. Ann Rheum Dis 48: 447-454. [Crossref]

31. Martin AR, Reddy R, Fehlings MG (2011) Dropped head syndrome: diagnosis and management. Evid Based Spine Care J 2: 41-47. [Crossref]

Copyright: (C2018 Oliveira FTM. This is an open-access article distributed under the terms of the Creative Commons Attribution License, which permits unrestricted use, distribution, and reproduction in any medium, provided the original author and source are credited. 